\title{
Multidrug-resistant bacterial isolates in infected wounds at Jimma University Specialized Hospital, Ethiopia
}

\author{
Girma Godebo ${ }^{1}$, Gebre Kibru ${ }^{2 *}$ and Himanot Tassew ${ }^{2}$
}

\begin{abstract}
Background: The term 'Multidrug-resistant' (MDR) applies to a bacterium that is simultaneously resistant to a number of antimicrobials belonging to different chemical classes. The effectiveness of currently available antmicrobial drugs is decreasing due to the increasing number of resistant strains causing infections so that available therapeutic options for such organisms are severely limited.
\end{abstract}

Objective: The aim of this study was to determine multidrug-resistance rate of bacterial isolates that caused wound infections.

Methods: A Hospital based cross-sectional study was conducted on 322 wound samples taken from consecutive patients seen at inpatient and outpatient department of Jimma University Specialized Hospital from June to December 2011. Swabs from surgical incisions, burns, abscess and traumatic wounds were collected aseptically using Levine's technique. Bacteriological culture and examination was done following standard microbiological techniques. Multidrug-resistance test was performed by disk diffusion method against 10 classes of antimicrobials. The data was analyzed for descriptive statistics using SPSS version 16 and Microsoft Excel.

Results: The overall MDR among gram positive and gram negative bacterial isolates were (77\%) and (59.3\%) respectively. About, $86.2 \%$ S.aureus and $28.6 \%$ of Coagulase negative Staphylococci became MDR. Nearly $30.1 \%$ of S.aureus was resistant to six classes of antimicrobials. The average MDR rate of Proteus, Klebsiella, and Providencia species was $74.8 \%, 69.6 \%$ and $75 \%$ in that order. Nearly, 30.8\% of Proteus sp, $32.6 \%$ of Klebsiella sp and $61 \%$ of Citrobacter sp were resistance to 4 classes each. Surprisingly, the average MDR rate for Citrobacter sp was 100\%. About (76.7\%) of S.aureus was Oxacillin/Methicillin resistant while (16.4\%) were Vancomycin resistant. Proteus species was the predominant isolates (27.9\%) followed by P.aeruginosa and S.aureus (19.3\%) and (19\%) respectively.

Conclusion: This study indicated that, the overall rate of MDR bacterial pathogens that caused wound infection was very high and many of the isolates were also identified as resistant to three or more classes of antimicrobials. Such widespread resistance to antimicrobial classes is something serious because a few treatment options remain for patients with wound infections. Periodic monitoring of etiology and antimicrobial susceptibility in areas where there is no culture facility is essential to assists physician in selection of chemotherapy.

Keywords: Multi drug resistance, Wound infection, Jimma, Ethiopia

\footnotetext{
* Correspondence: gebre.tiga@ju.edu.et

${ }^{2}$ Department of Medical Laboratory Sciences and Pathology, Jimma

University, P. O .Box 196, Jimma, Ethiopia

Full list of author information is available at the end of the article
} 


\section{Introduction}

The term multidrug-resistant (MDR) applies to a bacterium that is simultaneously resistant to a number of antimicrobial drugs belonging to different chemical classes or subclasses through various mechanisms [1]. One of the methods used by many authors and authorities to characterize organisms as MDR is based on the results of invitro antimicrobial susceptibility test. Antimicrobial drug resistance can be acquired as a result of mutation or acquisition of resistance genes via horizontal gene transfer, or can be an innate feature of an organism that is encoded chromosomally [2].

MDR in both the hospital and community environment are important concern to the clinician, patients and the pharmaceutical industries [3]. The widespread uses of antibiotics, together with the length of time over which the drugs have been available at market have led to major problems of the emergence of resistant organisms [4]. Antimicrobial drugs overuse, over dosing, drugs prescription with improper susceptibility test, self-medication and long duration of hospitalization was suggested to augment the problem of MDR in developing nations [5]. The Centers for Disease Control and Prevention (CDC) report regarding healthcare associated infection indicated that antimicrobial-resistant gram-negative bacilli are an emerging threat in the healthcare setting [6].

The study conducted on MDR among gram-negative pathogens that caused healthcare-associated infections in Atlanta, Georgia (USA) evaluated that $10 \%$ of P.aeruginosa, and $15 \%$ K.pneumoniae were found to be both resistant to 3 antimicrobial class. A much larger proportion, $60 \%$ of Acinetobacter baumannii isolates were resistant to at least 3 antimicrobial classes. Though less common than 3-class resistance, isolates with 4-class resistance were also seen in significant numbers and across regions [7].

Zeleke WT $[8,9]$ in his part indicated that over the past few years several studies in African countries had reported the presence of MDR strains of bacteria identified from clinical and environmental specimens. This was consecutively ascertained by findings of Olayinka et al., 2004 [10], Chikere et al., 2008 [11], Nkang et al., 2009 [5] all in Nigeria, Zeleke, 2002 in Ethiopia [8] and Anguzu et al., 2003 in Uganda [12]. A study conducted in one of the tertiary hospitals in Ethiopia also reported that about $51 \%$ of the gram negative bacterial isolates from open wounds were identified as MDR [13].

Such increase in both community and hospital-acquired antimicrobial-resistant bacteria is challenging the ability of effective patient treatment, prudent infection control and new treatment alternatives. According to Olayinka et al., constant bacteriological monitoring of the pathogens isolated from clinical specimens of patients in special units is necessary to draw attention of clinicians and infection control specialists to their current antibiotic susceptibility pattern and how often specific pathogens are isolated [10]. Blomberg and his colleague also suggested that the widely emerging MDR pathogens, in the absence of appropriate antimicrobial resistance surveillances and organized prevention strategies added worries in the incidence of infections among surgically operated, burn and other traumatic wound patients [14].

Though several studies have been conducted on etiology of wound infections in Ethiopian, none of them adequately addressed the extent of drug resistance of these isolates against different antimicrobial classes. Therefore, this study was intended to determine the magnitude of MDR bacteria identified from infected wounds in order to provide locally applicable data and to guide empirical therapy in area where culture and drug susceptibility testing facilities are scarce.

\section{Methods}

\section{Study design and population}

This facility based cross sectional study was conducted in Jimma University Specialized Hospital (JUSH) from May to December 2011. It is a 300 bedded hospital covers more than one million people living in the western regions of the country and gives specialty services in 11 wards and up to 400 patients attending outpatient department daily. Sociodemographic and clinical data of participant patients was obtained using semi-structured questionnaire.

\section{Wound sample collection and processing}

During the study period, a total of 322 infected wound samples were collected from consecutive patients seen both inpatient and outpatient departments. Wound beds were prepared before specimen collection by using Levine's technique [15], where the wound immediate surface exudates and contaminants were cleansed off with moistened sterile gauze and sterile normal saline solution. Dressed wounds were cleansed with non bacteriostatic sterile normal saline after removing the dressing. This technique is believed to be the best technique for swabbing open wounds and more reflective of tissue bioburden than swabs of exudates or swabs by other techniques. Cleansing the wounds prior to obtaining swab specimens was done in an effort to remove immediate surface contaminating organisms (bacteria). Thus the culture will be more likely to represent the microbiology in the deep wound compartment $[15,16]$. Aseptically the end of a sterile cotton-tipped applicator was rotated over $1 \mathrm{~cm}^{2}$ area for 5 seconds with sufficient pressure to express fluid and bacteria to surface from within the wound tissue as technique stated by Levine et al., 1976 [15] and Gardner et al., 2007 [16]. Double wound swabs were taken from each wound at a point in time to reduce the chance of occurrence of false-negative cultures and to increase the chance of recovering bacterial pathogens. It is also indicative of 
contamination in that if the two swab samples differ in types of organisms during presumptive test [17]. Then, wound specimens were transported to microbiology laboratory within 20 minutes by placing the swabs in to the sterile test tubes having $0.5 \mathrm{ml}$ of sterile normal saline solution. Bacteriological culture and examination was done following standard microbiological techniques [18].

\section{Multidrug-resistance testing}

Multidrug-resistance test was performed by disk diffusion method according to the criteria set by the (CLSI, 2010) [19] against different classes of antimicrobials: Cephalosporin class (cefoxitin, cefotaxim, ceftriaxone); Aminoglycosides class (gentamycin); Fluorquinolones class (ciprofloxacin, norfloxacin), Tetracycline class (doxycyclin); Folate Pathway Inhibitors (cotrimoxazole); Phenicols class (chloramphenicol); Penicillin class (oxacillin, ampicllin, penicillin); Glycopeptides class (vancomycin); Macrolides class (erythromycin) and Lincosamides class (clindamycin). Cloxacillin is not classified as individual class of drug rather it is classified as related drug to penicillinase resistant penicillin group like oxacillin and dicloxacillin. Gram positive bacteria were tested for drugs selected from all ten classes of antimicrobials where as gram negative were tested for seven classes excluding Glycopeptides, Macrolides and Lincosamides. The antimicrobial disks used for the test were all from (Oxoid Ltd. England). These drugs were selected based on the national list of medicines (FMHACA Ethiopia, 2010) to treat infections, prescription frequencies and availability. In order to monitor quality (potency) of disks, a standard strain of P.aeruginosa (ATCC-27853), S.aureus (ATCC-25923) and E.coli (ATCC-25922) were tested at regular interval and whenever new batches of antimicrobial discs were used.

\section{Data analysis}

The data was analyzed for descriptive statistics using SPSS version 16 and Microsoft Excel and presented in forms of tables. The results were interpreted in terms of frequencies, and percentages.

\section{Ethics}

This study was conducted after obtaining separate permission from Jimma University Ethical review Board and the Management Committee of Jimma University Specialized
Hospital. Informed consent was also pursued from patients or guardians of children and any information was kept confidential. All laboratory tests were done free of charge and their results were communicated to patients respective physician or nurses for beneficiary measures.

\section{Results \\ Multidrug-resistant patterns of isolates}

In this study, multidrug-resistant (MDR) status of gram positive and gram negative bacteria was tested against 10 and 7 classes of antimicrobials respectively. Accordingly, the overall rate of MDR among gram positive isolates was $77 \%$. This means, $86.2 \%$ of S.aureus and $28.6 \%$ of Coagulase negative Staphylococci (CNS) were becoming MDR. Moreover, 30.1\% of S.aureus showed resistance to six antimicrobial classes. About $21.4 \%$ of CNS was resistant to three classes as well (Table 1).

Then again, the overall MDR rate of gram negative bacteria was 59.3\%. Relatively higher rate of MDR was seen among Proteus, Klebsiella and Providencia species accounting average resistance of $74.8 \%, 69.6 \%$ and $75 \%$ respectively. Additionally, 24.3\% of Proteus and 25\% of Providencia species were resistant to three classes. About $32.6 \%$ of Klebsiella sp also showed resistant to four classes. Surprisingly, the average MDR rate of Citrobacter sp was found out to be $100 \%$ (Table 2).

\section{Antimicrobial resistance pattern to individual drugs}

The drug resistance profile of gram positive bacterial isolates tested for 16 antimicrobials showed that $94.5 \%$ of S.aureus was resistant to penicillin, $91.8 \%$ to ampicillin and $76.7 \%$ to oxacillin. About $16.4 \%$ of S.aureus became vancomycin resistant. Similarly, $68.3 \%$ of coagulase negative Staphylococcus (CNS) was resistance to both penicillin and ampicillin. Fortunately, CNS was $100 \%$ sensitive to many of the antimicrobial drugs tested (Table 3).

On the other hand, the resistance patterns of gramnegative bacteria isolates $(n=297)$ tested against nine antimicrobial drugs showed that P.aeruginosa was 97.3\%, $87.8 \%$, and $83.8 \%$ resistance to ampicillin, cotrimoxazole, and doxycycline respectively. Similarly, Citrobacter species showed 100\% resistance to ampicillin, cotrimoxazole and chloramphenicol and $88.9 \%$ to doxycycline. Furthermore, Proteus species showed $85 \%$ resistance to chloramphenicol and $75.7 \%$ to cotrimoxazole. With the exception of

Table 1 MDR gram positive bacteria identified from infected wounds in JUSH, June to December 2011

\begin{tabular}{|c|c|c|c|c|c|c|c|c|c|}
\hline \multirow{2}{*}{ Bacteria } & \multicolumn{8}{|c|}{ Antimicrobial classes resisted to No (\%) } & \multirow[t]{2}{*}{ Average } \\
\hline & R3 & R4 & R5 & R6 & R7 & R8 & R9 & R10 & \\
\hline S. aureus & $2(2.7)$ & $6(8.2)$ & $11(15.1)$ & $22(30.1)$ & $11(15.1)$ & $4(5.5)$ & $2(2.7)$ & $5(6.9)$ & $63(86.2)$ \\
\hline CNS & $3(21.4)$ & $0(0.0)$ & $1(7.1)$ & $0(0.0)$ & $0(0.0)$ & $0(0.0)$ & $0(0.0)$ & $0(0.0)$ & $4(28.6)$ \\
\hline Total & $5(5.8)$ & $6(6.9)$ & 12(13.8) & $22(25.3)$ & $11(12.6)$ & $4(4.6)$ & $2(2.3)$ & $5(5.8)$ & $67(77.0)$ \\
\hline
\end{tabular}

Key: R3 - R10 = resistance of bacteria to $3,4,5,6,7,8,9$ or 10 classes of antimicrobials tested. 
Table 2 MDR gram negative bacteria identified from infected wounds in JUSH, June to December 2011

\begin{tabular}{|c|c|c|c|c|c|c|}
\hline \multirow{2}{*}{ Bacteria } & \multicolumn{5}{|c|}{ Classes of antimicrobial resisted to No (\%) } & \multirow{2}{*}{$\begin{array}{c}\text { Average } \\
\text { No (\%) }\end{array}$} \\
\hline & R3 & R4 & R5 & R6 & R7 & \\
\hline Proteus spp & $26(24.3)$ & $33(30.8)$ & $12(11.2)$ & $5(4.8)$ & $4(3.7)$ & $80(74.8)$ \\
\hline P. aeruginosa & $11(14.9)$ & $9(12.2)$ & $3(4.1)$ & - & $4(5.4)$ & $27(36.5)$ \\
\hline Klebsiella spp. & $3(6.5)$ & 15(32.6) & $1(2.2)$ & - & 13(28.3) & $32(69.6)$ \\
\hline E. coli & $3(10.0)$ & $3(10.0)$ & $1(3.3)$ & - & - & $7(23.3)$ \\
\hline Citrobacter & $1(5.5)$ & $11(61.0)$ & $1(5.6)$ & $3(16.7)$ & $2(11.1)$ & $18(100)$ \\
\hline Providencia spp. & $2(25.0)$ & $1(12.5)$ & $2(25.0)$ & - & $1(12.5)$ & $6(75.0)$ \\
\hline Acinetobacter spp. & - & $2(28.6)$ & $1(14.3)$ & - & $1(14.3)$ & $4(57.2)$ \\
\hline M. morganii & - & $1(20.0)$ & $1(20.0)$ & - & - & $2(40.0)$ \\
\hline Total & $46(15.5)$ & $75(25.2)$ & $22(7.4)$ & $8(2.7)$ & $25(8.4)$ & 176(59.3) \\
\hline
\end{tabular}

Key: R3- R7 = resistant to 3, 4, 5, 6 or 7 classes of antimicrobials tested.

Citrobacter and Proteus sp, all other gram negative isolates in this study showed relatively low resistance to ceftriaxone, cefotaxim, norfloxacin, ciprofloxacin and chloramphenicol (Table 4).

\section{Etiology of wounds}

In this study, $96.3 \%$ of wound samples were culture positive of which $22.9 \%$ had multiple bacterial infections (data not shown). As it is indicated in Table 5, the most prevalent wound type was trauma (37.8\%) followed by abscess $(29.8 \%)$ and the least was cellulites (1\%). Proteus species was the most frequently isolated bacteria accounting $27.9 \%$ followed by $P$. aeruginosa and S. aureus with rate of $19.3 \%$ and $19 \%$ respectively.

\section{Discussion}

In this study, the overall MDR rate of gram positive isolates (i.e. S.aureus and CNS) was 77\%. This finding was slightly higher than $65.2 \%$ [13] and 52.7\% [20] MDR rate documented for these two groups of bacteria in Ethiopia. But it is lower than $100 \%$ and $98.6 \%$ MDR reported by Mulu et al., 2012 [21] and Biadglegne et al., 2009 [22] in the same country respectively. The possible explanation for such disparity might be difference in study population where previous studies solely included hospitalized inpatients where higher MDR strains are expected. About $86.2 \%$ of S.aureus also became MDR of which $6.9 \%$ were resistant to all (ten) classes of antimicrobials tested. And again, $15.1 \%$ and $30.1 \%$ of them were resistant to seven and six classes respectively. Similarly, $28.6 \%$ of CNS showed MDR of which $21.4 \%$ were resistant to three classes (penicillin, tetracycline and phenicoles).

On the other hand, the overall MDR rate of gram negative bacteria tested for seven classes of antimicrobial drugs was $59.3 \%$. This finding goes inline to study in Ethiopia where 51\% MDR gram negative bacterial isolates from open wounds were reported (13). Moreover, the $100 \%$ MDR Citrobacter seen in this study concise with $100 \%$ MDR rate reported both in Ethiopia [22] and Pakistan [23], and $86.95 \%$ in Nepal [24]. Nearly $15 \%$ of P.aeruginosa was found to be resistant to 3 antimicrobial classes (Table 5) which is a bit higher than $10 \%$ report made by Kellen et al., [7]. In that study, $15 \%$ of $K$. pneumoniae was reported as resistant to 3 antimicrobial classes which is higher than $6.5 \%$ obtained in the present study.

Regarding the resistance profile of isolates to individual drugs indicated that S.aureus showed an average resistance rate of $54.1 \%$ to most of the antimicrobial drugs tested (Table 3). This finding agrees with previous studies done elsewhere in Ethiopia [21,25-27] where average resistance of $52 \%$ up to $75 \%$ were recorded. About $76.7 \%$ of S.aureus was also oxacillin/methicillin resistant (MRSA). This finding was in agreement with findings in Ethiopia [28], Nepal [29], and Italy [30] where $83 \%, 60.6 \%$ and $74.2 \%$ were

Table 3 Antimicrobial drugs resistance pattern of gram positive bacteria identified from infected wounds in JUSH, June to December 2011

\begin{tabular}{|c|c|c|c|c|c|c|c|c|c|c|c|c|c|c|c|c|c|}
\hline \multirow{2}{*}{ Bacteria } & \multicolumn{16}{|c|}{ Drugs No (\%) resistance to } & \multirow{2}{*}{$\begin{array}{c}\text { Total } \\
(\%)\end{array}$} \\
\hline & OX & FOX & $\mathrm{OB}$ & $E$ & $\mathrm{CD}$ & $\mathbf{P}$ & AP & DO & CRO & NOR & CTX & TS & $\mathrm{CN}$ & VA & CIP & C & \\
\hline & $\begin{array}{c}56 \\
(76.7)\end{array}$ & $\begin{array}{c}21 \\
(28.8)\end{array}$ & $\begin{array}{c}57 \\
(78.1)\end{array}$ & $\begin{array}{c}58 \\
(79.4)\end{array}$ & $\begin{array}{c}62 \\
(85.0)\end{array}$ & $\begin{array}{c}69 \\
(94.5)\end{array}$ & $\begin{array}{c}67 \\
(91.8)\end{array}$ & $\begin{array}{c}60 \\
(82.2)\end{array}$ & $\begin{array}{c}15 \\
(20.5)\end{array}$ & $\begin{array}{c}12 \\
(16.4)\end{array}$ & $\begin{array}{c}26 \\
(35.6)\end{array}$ & $\begin{array}{c}44 \\
(60.3)\end{array}$ & $\begin{array}{c}12 \\
(16.5)\end{array}$ & $\begin{array}{c}12 \\
(16.4)\end{array}$ & $\begin{array}{c}10 \\
(13.7)\end{array}$ & $\begin{array}{c}51 \\
(69.9)\end{array}$ & 4.1) \\
\hline N & $1(7.1)$ & $0(0.0)$ & $\begin{array}{c}3 \\
(21.4)\end{array}$ & $0(0.0)$ & $0(0.0)$ & $\begin{array}{c}9 \\
(68.3)\end{array}$ & $\begin{array}{c}9 \\
(68.3)\end{array}$ & $\begin{array}{c}5 \\
(35.7)\end{array}$ & $\begin{array}{c}2 \\
(14.3)\end{array}$ & $0(0.0)$ & $\begin{array}{c}2 \\
(14.3)\end{array}$ & $\begin{array}{c}5 \\
(35.7)\end{array}$ & $0(0.0)$ & $0(0.0)$ & $0(0.0)$ & $\begin{array}{c}4 \\
(28.6)\end{array}$ & 17.9) \\
\hline
\end{tabular}


Table 4 Antimicrobial drug resistance patterns of gram negative bacteria identified from infected wounds in JUSH, June to December, 2011

\begin{tabular}{|c|c|c|c|c|c|c|c|c|c|c|}
\hline \multirow{2}{*}{ Bacteria } & \multicolumn{9}{|c|}{ Drugs resisted to No (\%) } & \multirow{2}{*}{$\begin{array}{c}\text { Average } \\
\text { (\%) }\end{array}$} \\
\hline & AP & DO & CRO & CTX & NOR & CIP & $\mathrm{CN}$ & TS & C & \\
\hline Proteus spp. $(n=107)$ & $77(72.0)$ & $80(74.8)$ & $8(7.5)$ & $14(13.1)$ & 6(5.6) & $8(7.5)$ & $35(32.7)$ & $81(75.7)$ & $91(85.0)$ & $(39.9)$ \\
\hline P.aeruginosa $(n=74)$ & $72(97.3)$ & $62(83.8)$ & $7(9.5)$ & $9(12.2)$ & $5(6.8)$ & $4(5.4)$ & $8(10.8)$ & 65(87.9) & $55(74.3)$ & $(43.5)$ \\
\hline Klebsiella spp. $(\mathrm{n}=46)$ & $32(69.6)$ & $36(78.3)$ & $13(28.3)$ & 14(30.4) & $13(28.3)$ & 13(28.3) & 13(28.3) & $30(65.1)$ & $32(69.6)$ & $(47.3)$ \\
\hline E. coli $(\mathrm{n}=30)$ & $23(76.7)$ & $7(23.3)$ & $20(66.7)$ & $20(66.7)$ & $1(3.3)$ & $1(3.3)$ & $0(0.0)$ & $6(20.0)$ & $4(13.3)$ & (30.4) \\
\hline Citrobacter spp $(n=18)$ & $18(100)$ & 16(88.9) & $3(16.7)$ & $5(27.8)$ & $2(11.1)$ & $2(11.1)$ & $6(33.3)$ & 18(100) & $18(100)$ & $(54.3)$ \\
\hline Providencia $\operatorname{spp}(n=8)$ & $7(87.5)$ & $4(50.0)$ & $2(25.0)$ & $3(37.5)$ & $1(12.5)$ & $1(12.5)$ & $2(25.0)$ & $6(75.0)$ & $7(87.5)$ & $(45.8)$ \\
\hline Acinetobacter spp $(n=7)$ & $4(57.1)$ & $3(42.9)$ & $4(57.1)$ & $4(57.1)$ & $1(14.3)$ & $1(14.3)$ & $3(42.9)$ & $3(42.9)$ & $4(57.1)$ & $(42.9)$ \\
\hline M. morganii $(\mathrm{n}=5)$ & $5(100)$ & $5(100)$ & $0(0.0)$ & $1(20.0)$ & $0(0.0)$ & $0(0.0)$ & $0(0.0)$ & $2(40)$ & $2(40.0)$ & $(33.4)$ \\
\hline E. cloacae $(n=2)$ & $0(0.0)$ & $0(0.0)$ & $0(0.0)$ & $0(0.0)$ & $0(0.0)$ & $0(0.0)$ & $0(0.0)$ & $0(0.0)$ & $0(0.0)$ & $0(0.0)$ \\
\hline
\end{tabular}

Key: AP = Ampicllin, DO = Doxycyclin, $\mathrm{CRO}=$ Ceftriaxone, NOR = Norfloxacin, CTX = Cefotaxim, TS = Cotrimoxazole, CN = Gentamycin,

$\mathrm{CIP}=$ Ciprofloxacin, $\mathrm{C}=$ Chloramphenico

documented in that order. But, this was much lower than $100 \%$ resistant S.aureus to oxacillin reported by Yishak et al., 2009 in Ethiopia [13]. And yet the 76.7\% was incomparably higher than findings of Amare et al., 2011 in Ethiopia [31], Anguzu et al., in Uganda [12] and Wibbenmeyer et al., 2006 in USA [32] where 34.6\%, 25\% and 46.2\% MRSA were reported respectively. In this study, oxacillin resistant S. aureus (MRSA) were found out to be susceptible to cefoxitin, cefotaxime and ceftriaxone. The cause of oxacillin resistance in this case might not be because of macA gene instead, other mechanisms of resistance like impermeability of the membrane, deposition of high fat cover on cell wall, deformation/mutation of porine proteins extra could be reasons for such observed descripancies.

Moreover, the $16.4 \%$ vancomycin resistance rate of $S$. aureus in this study were lower than that of $40 \%$ reported by Mimejad et al., 2008 in Iran [27] and 21\% by Flamm et al., 2004 in Nepal [29]. But, it was much higher when compared with $3.6 \%$ report made also in Iran [33]. However, such incidence of vancomycin resistant Staphylococci in hospital as well as in community are alarming because vancomycin is currently the main antimicrobial agent available to treat life-threatening infections with MRSA as indicated by CDC,2002 [34]. Unlike S.aureus, CNS was $100 \%$ sensitive for cefoxitin, erythromycin, clindamycin, norfloxacin, gentamycin, vancomycin, and ciprofloxacin. Similar high rate of susceptibility of CNS to these drugs were reported from Italy [30] and in Ethiopia (27).

Among gram negative isolates, Proteus species, $P$. aeruginosa and Klebsiella species showed high resistance (>65\%) to doxycycline, cotrimoxazole and chloramphenicol. In a similar studies up to $100 \%$ resistance rate was reported in Ethiopia [9] and 83\% in Pakistan [23].

Table 5 Frequency of pathogenic bacteria isolates by wound types at JUSH from June to December 2011

\begin{tabular}{|c|c|c|c|c|c|c|c|}
\hline \multirow{2}{*}{ Bacteria } & \multicolumn{6}{|c|}{ Wound type No (\%) } & \multirow{2}{*}{ Total } \\
\hline & Surgical & Abscess & Trauma & Burn & Osteomyelitis & Cellulites & \\
\hline Proteus sp & $19(4.9)$ & $45(11.7)$ & $26(6.8)$ & $13(3.4)$ & $3(0.9)$ & $1(0.3)$ & $107(27.9)$ \\
\hline P.aeruginosa & $8(2.1)$ & $11(2.9)$ & $45(11.7)$ & $8(2.1)$ & $2(0.5)$ & $0(0.0)$ & $74(19.3)$ \\
\hline S.aureus & 15(3.9) & $23(6.0)$ & $23(6.0)$ & $7(1.8)$ & $3(0.9)$ & $2(0.5)$ & 73(19.0) \\
\hline Klebsiella sp & $1(0.3)$ & $1(0.3)$ & $30(7.8)$ & 14(3.6) & $0(0.0)$ & $0(0.0)$ & $46(12.0)$ \\
\hline E.coli & $3(0.9)$ & $20(5.2)$ & $5(1.3)$ & $2(0.5)$ & $O(0.0)$ & $0(0.0)$ & $30(7.9)$ \\
\hline Citrobacter sp & $5(1.3)$ & $5(1.3)$ & $4(1.0)$ & $4(1.0)$ & $\mathrm{O}(0.0)$ & $\mathrm{O}(0.0)$ & $18(4.7)$ \\
\hline CNS & $2(0.5)$ & $6(1.6)$ & $5(1.3)$ & $1(0.3)$ & $0(0.0)$ & $\mathrm{O}(0.0)$ & 14(3.6) \\
\hline Providencia sp & $2(0.5)$ & $3(0.8)$ & $0(0.0)$ & $0(0.0)$ & $0(0.0)$ & $0(0.0)$ & $8(2.1)$ \\
\hline Acinetobacter & $1(0.3)$ & $1(0.3)$ & $1(0.3)$ & $2(0.5)$ & $1(0.3)$ & $1(0.3)$ & $7(1.8)$ \\
\hline M.morganii & $3(0.8)$ & $0(0.0)$ & $1(0.3)$ & $0(0.0)$ & $1(0.3)$ & $\mathrm{O}(0.0)$ & $5(1.3)$ \\
\hline E.cloacae & $0(0.0)$ & $0(0.0)$ & $2(0.5)$ & $0(0.0)$ & $0(0.0)$ & $0(0.0)$ & $2(0.5)$ \\
\hline Total & $59(15.4)$ & 115(29.9) & $145(37.8)$ & $51(13.3)$ & $10(2.6)$ & $4(1.0)$ & $384(100)$ \\
\hline
\end{tabular}


In this study the most frequently isolated bacteria were Proteus species $107(27.9 \%)$ followed by P.aeruginosa 74 (19.3\%) and S.aureus 73(19\%). The possible reason for the high frequency is that these bacteria are normal flora in healthy person when they get breaks on skins and soft tissue in any of mechanical cases or burns (especially P.aeruginosa) they can easily disseminate as it was indicated by Khanal et al., 2010 in Nepal [29] and by Flamm et $a l$., in United States [35]. Moreover, these bacteria are commonly found in the hospital environment [8] which might increase wound infection rate and cross contamination among admitted patients.

\section{Conclusion}

It is known that antimicrobial resistance is a growing global problem. However, the increased proportion of MDR seen in this study was considered as alarming because only a few treatment options remain for wound infections. About $76.7 \%$ of S.aureus was oxacillin/methicillin resistant (MRSA), of which $16.4 \%$ was vancomycin resistant (VRSA). Such incidence of vancomycin resistant Staphylococci is worrisome to the clinicians as it is currently the main antimicrobial agent available to treat life-threatening infections with MRSA. As majority of bacterial isolates showed widespread resistance against different antimicrobial classes, treatment of wound infections has to be made based on the culture and susceptibility results. Nevertheless, if one could not wait the culture results, ampicillin, penicillin, methicillin, trimethoprim-sulphamethoxazole, doxycyclin and chloramphenicol are not good choices to treat wound infections. Moreover, periodic monitoring of etiology and antimicrobial susceptibility of isolates from wounds in hospital settings is beneficial to the patient and assists physician in selection of chemotherapy in areas where no culture facilities.

\section{Competing interests}

The authors declare that they have no competing interests.

\section{Authors' contributions}

GG, GK and HT participated in design, laboratory analysis, interpretation of the data and write up of the manuscript. All the authors read and approved the final version.

\section{Acknowledgements}

The authors would like to acknowledge patients for their willingness and Medical Laboratory Sciences and Pathology Department, Jimma University for allowing its laboratory facilities.

\section{Funding}

The study was funded by Jimma University, Ethiopia.

\section{Author details}

${ }^{1}$ School of Medicin, Wachemo University, Hosaena, Ethiopia. ${ }^{2}$ Department of Medical Laboratory Sciences and Pathology, Jimma University, P. O .Box 196, Jimma, Ethiopia.

Received: 20 February 2013 Accepted: 30 June 2013

Published: 23 July 2013

\section{References}

1. Magiorakos AP, Srinivasan A, Carey RB, et al: Multidrug-resistant, extensively drug-resistant and pandrug-resistant bacteria: an international expert proposal for interim standard definitions for acquired resistance. Clin Microbiol Infect 2012, 18:268-281.

2. Livermore DM: Multiple mechanisms of antimicrobial resistance in Pseudomonas aeruginosa: our worst nightmare? Clin Infect Dis 2002, 34:634-640.

3. Ussiri1 EV, Mkony CA, Aziz MR: Surgical wound infection in clean-contaminated and contaminated laparotomy wounds at Muhimbili National Hospital. East Cent Afr j Surg 2005, 10:1-5.

4. Buteera AM, Byimana J: Principles of management of open fractures. East Cent Afr j Surg 2009, 14:1-119.

5. Nkang AO, Okonko IO, Mejeha OK, et al: Assessment of antibiotics susceptibility profiles of some selected clinical isolates from laboratories in Nigeria. J Microbiol Antimicrobi 2009, 1:19-26.

6. Edwards JR, Peterson KD, Mu Y, et al: National Healthcare Safety Network (NHSN) report: data summary for 2006 through 2008, issued December 2009. Am J Infect Control 2009, 37(10):783-805.

7. Kallen AJ, Hidron Al, Patel J, Srinivasan A: Multidrug resistance among gram-negative pathogens that caused healthcare-associated infections reported to the National Healthcare Safety Network, 2006-2008. Infect Control Hosp Epidemiol 2010, 31(5):258-532.

8. Zeleke WT: Multiple antimicrobial resistance in bacterial isolates from clinical and environmental sources of Jimma Hospital. Ethiop J scien 2002, 25:295-302.

9. Zeleke WT: Multiple antimicrobial resistance in gram negative bacilli isolated from clinical specimens, Jimma Hospital. Ethiop Med J 2001, 39:305-312.

10. Olayinka AT, Onile BA, Olayinka BO: Prevalence of multi-drug resistant (mdr) Pseudomonas aeruginosa isolates in surgical units of Ahmadu Bello University teaching hospital, Zaria, Nigeria: an indication for effective control measures. Ann Afr Med 2004, 3:13-16.

11. Chikere $\mathrm{CB}$, Chikere $\mathrm{BO}$, Omoni $\mathrm{VT}$ : Antibiogram of clinical isolates from a hospital in Nigeria. Afr J Biotech 2008, 7:4359-4363.

12. Anguzu JR, Olila D: Drug sensitivity patterns of bacterial isolates from septic post-operative wounds in a regional referral hospital in Uganda. Int J Antimicrobial Agents 2003, 4:18-31.

13. Yishak A, Biruk LW: Microbial susceptibility of bacteria isolated from open fracture wounds presenting to the black-lion hospital, Addis Ababa University. Afr J Microbiol Res 2009, 3:939-951.

14. Blomberg B, Mwakagile DSM, Urassa WK, et al: Surveillance of antimicrobial resistance at a tertiary hospital in Tanzania. BMC Publ Health 2004, 4:45. Available at: http://www.biomedcentral.com/1471-2458/ 4/45/ assessed Feb 10/2011.

15. Levine NS, Lindberg RB, Mason AD Jr, Pruitt BA Jr: The quantitative swab culture and smear: a quick, simple method for determining the number of viable aerobic bacteria on open wounds. J Trauma 1976, 16:89-94.

16. Gardner SE, Frantz R, Hillis SL, Park H, Scherubel M: Diagnostic validity of semiquantitative swab cultures. Wounds 2007, 19:31-38.

17. Bori G, Soriano A, Garcia S, Mallofre C, Riba J, Mensa J: Usefulness of histological analysis for predicting the presence of microorganisms at the time of reimplantation after hip resection arthroplasty for the treatment of infection. J Bone Joint Surg Am 2007, 89:1232-1261.

18. Cheesbrough M: District laboratory practice in tropical countries volume II: microbiology. Cambridge (UK): Cambridge University Press; 2006:1-479.

19. Clinical and Laboratory Standards Institute (CLSI): Performance standards for antimicrobial susceptibility testing. Twent Informational Supp/ 2010, 29:1-160.

20. Azene MK, Beyene BA: Bacteriology and antibiogram of pathogens from wound infections at Dessie Laboratory, North East Ethiopia. Tanzan J Health Res 2011, 13:1-10.

21. Mulu W, Kibru G, Beyne G, Damtie M: Postoperative nosocomial infections and antimicrobial resistance pattern of bacteria isolates among patients admitted at Felege Hiwot Referral Hospital, Bahirdar, Ethiopia. Ethiop J Health Sci 2012, 22:1-12.

22. Biadglegne F, Abera B, Alem A, et al: Bacterial isolates from wound infection and their antimicrobial susceptibility pattern in Felege Hiwot Referral Hospital, North West Ethiopia. Ethiop J health Sci 2009, 19:173-177.

23. Dilnawaz SS, Abbas HZ, Khurram S, et al: Post surgical wound infections: a study on threats of emerging resistance. Pak J Pharmacol 2003, 20:31-41. 
24. Thapa B, Karn D, Mahat K: Emerging trends of nosocomial Citrobacter species surgical wound infection: concern for infection control. NJDVL 2010, 9:10-14.

25. Mulu A, Moges F, Tessema B, Kassu A: Pattern and multiple drug resistance of bacterial pathogens isolated from wound infection at University of Gondar Teaching Hospital. Ethiop Med J 2006, 44:125-131.

26. Messele G, Woldemedhin $Y$, Demissie M, et al: Common causes of nosocomial infections and their susceptibility patterns in two hospitals in Addis Ababa. Ethiop J Health Biomed Sci 2009, 2:3-8.

27. Mimejad R, Fallahi S, Kiani J, Jeddi F, Khoobdel M, Jonaidi N, Alaeddini F: Epidemiology assessment of bacterial agents in osteomyelitis and their antibiotic resistance pattern determination. J Biol Sci 2008, 8:478-481.

28. Gebre-Sealsssie S: Antimicrobial resistance patterns of clinical bacterial isolates in southwestern Ethiopia. Ethiop Med J 2007, 45:363-370.

29. Khanal LK, Jha BK: Prevalence of Methicillin resistant Staphylococcus aureus (MRSA) among skin infection cases at a hospital in Chitwan, Nepal. Nepal Med Coll J 2010, 12:224-228.

30. Giacometti A, Cirioni O, Schimizzi AM, et al: Epidemiology and microbiology of surgical wound infections. J Clin Microbiol 2000, 38:918-922.

31. Amare B, Abdurrahman Z, Moges B, et al: Postoperative surgical site bacterial infections and drug susceptibility patterns at Gondar University Teaching Hospital, Northwest Ethiopia. J Bacteriol Parasitol 2011, 2:1-6.

32. Wibbenmeyer $L$, Danks $R$, Faucher $L$, et al: Prospective analysis of nosocomial infection rates, antibiotic use and patterns of resistance in a burn population. Amer J Burn Care Res 2006, 27:152-160.

33. Saderi H, Owlia P, Shahrbanooie R: Vancomycin resistance among clinical isolates of Staphylococcus aureus. Arch Iranian Med 2005, 8:100-103.

34. Bataineh AB: Resistance of Staphylococcus aureus to Vancomycin in Zarqa, Jordan. Pak J Med Sci 2006, 22:144-148.

35. Flamm RK, Weaver MK, Thornsberry C, et al: Factors associated with relative rates of antibiotic resistance in Pseudomonas aeruginosa isolates tested in clinical laboratories in the United States from 1999 to 2002. Antimicrob Agents Chemother 2004, 7:2431-2436.

doi:10.1186/1476-0711-12-17

Cite this article as: Godebo et al:: Multidrug-resistant bacterial isolates in infected wounds at Jimma University Specialized Hospital, Ethiopia. Annals of Clinical Microbiology and Antimicrobials 2013 12:17.

\section{Submit your next manuscript to BioMed Central and take full advantage of:}

- Convenient online submission

- Thorough peer review

- No space constraints or color figure charges

- Immediate publication on acceptance

- Inclusion in PubMed, CAS, Scopus and Google Scholar

- Research which is freely available for redistribution

Submit your manuscript at www.biomedcentral.com/submit
(O) Biomed Central 